\section{Nicotinamide and insulin sensitivity}

Dear Sir,

Interest in the potential for large daily doses of nicotinamide to prevent Type 1 (insulin-dependent) diabetes mellitus [1], and the observation that the related substance nicotinic acid may disturb insulin action [2], led us to evaluate the effect of nicotinamide on insulin sensitivity, glucose disappearance rate $\left(\mathrm{K}_{\mathrm{g}}\right)$, and acute insulin response to glucose (AIRG) in healthy volunteers. In the same subjects we also measured serial blood levels of nicotinamide and its main metabolite N-methyl-2-pyridone-5-carboxamide (2-PYR) following ingestion of a single dose of a sustained-release preparation of nicotinamide (Enduramide: Endurance Products Co., Tigard, Ore., USA). These data have not been previously reported.

Following ethics committee approval and informed consent, nine adults (five males, four females, mean [SD] age 35.1 [10] years, mean [SD] body mass index $27.5[5.3] \mathrm{kg} / \mathrm{m}^{2}$ ) underwent an insulin sensitivity study by the minimal model technique [3]. Subjects were then given Enduramide twice daily at a total dose of $1.2 \mathrm{~g}_{\text {per }} \mathrm{m}^{2}$ surface area per day for 7 days, after which insulin sensitivity was remeasured. Females were either post-menopausal (two subjects) or at the start of their menstrual cycle for the first insulin sensitivity study. Levels of 2-PYR and nicotinamide were determined by high pressure liquid chromatography in ultrafiltered plasma [4] at $0,1,2$, $4,6,8$, and $12 \mathrm{~h}$ post-ingestion of the first dose of Enduramide.

No statistically significant differences were seen in insulin sensitivity (mean paired difference [7-day value - baseline] = $-7.0 \mathrm{~min}^{-1} \cdot[\mathrm{nmol} / \mathrm{ml}]^{-1}$, Wilcoxon signed rank statistic $=-10.5$, $p=0.25), K_{\mathrm{g}}$ (mean paired difference $=-0.11 \% / \mathrm{min}$, Wilcoxon signed rank statistic $=-3.5, p=0.73$ ), or AIRG (mean paired difference $=531 \mathrm{pmol} \cdot \mathrm{min}$, Wilcoxon signed rank statistic $=12.5$, $p=0.16)$. By Student's $t$-distribution, the corresponding $95 \%$ con-

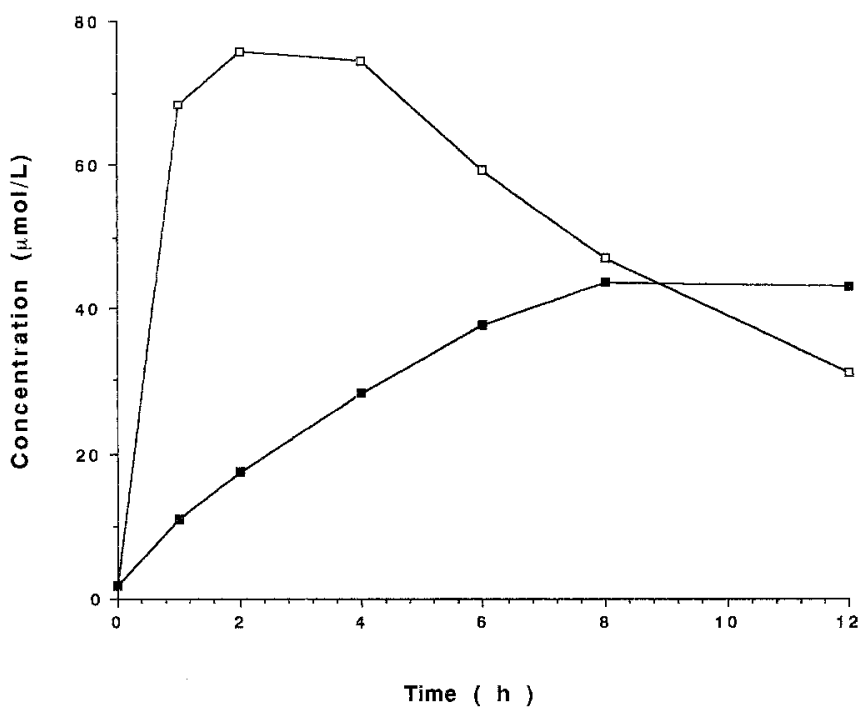

Fig. 1. Plasma nicotinamide $\square$ and N-methyl-2-pyridone-5-carboxamide (2-PYR) $\mathbf{\square}$ in a representative patient fidence limits on the mean paired differences were $(-19.3$, $5.3) \mathrm{min}^{-1},(-0.7,0.5) \% / \mathrm{min}$, and $(-247,1309) \mathrm{pmol} \cdot \mathrm{min}$. Representative plasma levels of nicotinamide and 2-PYR over $12 \mathrm{~h}$ are given in Figure 1.

These data suggest that sustained-release nicotinamide given twice daily is adequate to maintain continuous presence of the drug in the blood. The biological importance of this cannot be defined from these observations and will probably rest with results of randomized control trials testing the efficacy of nicotinamide for preventing Type 1 diabetes in patients at high-risk for the disease [1]. The data also suggest that nicotinamide given at a dosage comparable to that reported to be effective in arresting pancreatic betacell loss in Type 1 diabetes $[1,5]$ does not affect insulin action or secretion in healthy, non-diabetic adults. However, generalization of these findings to patients with subclinical Type 1 diabetes must consider the relatively small sample size and the absence of children in the study group. Within conventional levels of statistical certainty, a fall in insulin sensitivity from nicotinamide use as large as 19 sensitivity index units cannot be excluded. Such a change may be clinically important, suggesting that serial determination of insulin sensitivity should be considered for adult subjects (at the least, given the practical difficulties of measuring insulin sensitivity in children) enrolled into clinical trials of nicotinamide for prevention of Type 1 diabetes.

Yours sincerely,

T. L. Paul, I. M. Hramiak, J. L. Mahon, D. Freeman, P. Atkison, D. T. Finegood and J. Dupre

\section{References}

1. Chase P, Dupre J, Mahon JL et al. (1992) Nicotinamide and prevention of IDDM. Lancet 339: 1051 (Letter)

2. Kahn SE, Beard JC, Schwartz MW et al. (1989) Increased B-cell secretory capacity as mechanism for islet-adaptation to nicotinicacid-induced insulin resistance. Diabetes 38: 562-568

3. Bergman RN, Beard J, Chen M (1986) Minimal modelling method. Assessment of insulin sensitivity and B-cell fraction in vivo. In: Clarke W, Larner J, Pohl SL (eds) Methods in diabetes research: clinical methods. Vol 2. Wilcy, Chichester New York Brisbane Toronto, pp 15-24

4. McKee RW, Kang-Lee YA, Panagua M, Swendseid NE (1982) Determination of nicotinamide and metabolic products in urine by high performance liquid chromatography. J Chromatogr 230 : 309-317

5. Vague P, Picq R, Bernal M, Lassmann-Vague V, Vialettes B (1989) Effect of nicotinamide on the residual insulin secretion in type 1 (insulin-dependent) diabetes patients. Diabetologia 32: 316-321

6. Friedman LM, Furberg CD, DeMets DL (1985) Fundamentals of clinical trials. PSG Publishing Company, Littleton, $\mathrm{p} 96$

Dr. T.L.Paul

Room 3 TU2

University Hospital

339 Windermere Road

London, Ontario

Canada N6A 5A5 